\title{
A MORTE E O MORRER: a reação dos profissionais enfermeiros
}

DOI: 10.22289/2446-922X.V8N1A6

\author{
Karine Klaus ${ }^{1}$ \\ Lissandra Baggio
}

\section{RESUMO}

Este trabalho parte do pressuposto que a morte é um fenômeno significativo para os que ficam, especialmente o profissional enfermeiro que se dedicou a dar assistência e prestar cuidados ao sujeito que morreu. É inevitável ao profissional enfermeiro - enquanto ser humano - não criar vínculo com seu paciente, especialmente se possui o dever de prestar assistência e cuidados a ele, pois para o cuidado com outrem se faz necessária a empatia. O estudo teve o objetivo de verificar qual a reação dos profissionais enfermeiros diante do processo de morrer e de morte de seus pacientes, compreender a concepção de morte dos enfermeiros e descrever os sentimentos despertados pelo fenômeno morte. Com relação aos aspectos metodológicos, trata-se de um estudo de caso múltiplo, qualitativo, de caráter exploratório. Participaram deste estudo dezesseis enfermeiros com pelo menos seis meses de atuação em unidades de terapia intensiva e unidades de emergência. Para coleta de dados foi utilizada uma entrevista semiestruturada e um instrumento de avaliação da ansiedade. Destaca-se que foram adotados todos os procedimentos éticos. O estudo demonstrou o uso da negação e racionalização como defesas psíquicas. Ficou evidenciada a angústia na comunicação da morte do paciente e a necessidade do apoio do serviço de psicologia. Sugeriu-se melhorias na graduação dos cursos de enfermagem e criação de espaços terapêuticos.

Palavras-chave: Tanatologia; Morte; Enfermeiros.

\section{DEATH AND THE DYING PROCESS: the reaction of nursing professionals}

\section{ABSTRACT}

The present study assumes that death is a significant phenomenon for those who stay, especially the nursing professional who has devoted itself to provide assistance and care for the individual who has died. It is unavoidable for the nurse- whilst a human being - not to create bonds with patients, especially if it has the duty to provide assistance and care, the care for others requires empathy. The study intended to verify what reaction the nurses would display facing the process of death and death itself of their own patients, to understand the meaning of death for the nurses and describe the feelings provoked by the phenomenon of death. In relation to the methodological aspects, it is a qualitative, of exploratory characteristics and multiple case study. Seventeen nurses have participated in the study with a six-month minimum of intensive care and emergency units experience. For data collecting it has been used a semi-structured interview and an anxiety evaluation instrument. All ethical procedures were adopted. The study has demonstrated the use of

${ }^{1}$ Endereço eletrônico de contato: karineklauspsi@gmail.com

Recebido em 16/11/2021. Aprovado pelo conselho editorial para publicação em 06/01/2022.

Rev. Psicol Saúde e Debate. Jan., 2022:8(1): 74-96. 
denial and rationalization as psychological defenses. It was evident the anguish in the communication of the patient's death and the necessity of psychological services support. It was suggested improvements in the nursing schools and the creation of therapeutic environments.

Keywords: Thanatology; Death; Nurses.

\section{LA MUERTE Y EL MORIR: la reacción de los profesionales enfermeros}

\section{RESUMEN}

Este trabajo parte de la suposición que la muerte es un fenómeno significativo para los que se quedan, especialmente el profesional enfermero que se dedicó a dar asistencia y prestar cuidados al sujeto que murió. Es inevitable al profesional enfermero - mientras ser humano - no criar vínculo con su paciente, especialmente si posee el deber de prestar asistencia y cuidados a él, pues para el cuidado con los demás se hace necesaria la empatía. El estudio tuvo el objetivo de verificar cual la reacción de los profesionales enfermeros frente al proceso de morir y de la muerte de sus pacientes, comprehender la concepción de muerte de los enfermeros y describir los sentimientos despertados por el fenómeno muerte. Con relación a los aspectos metodológicos, se trata de un estudio de caso múltiplo, cualitativo, de carácter exploratorio. Participaron de este estudio dieciséis enfermeros con por lo menos seis meses de actuación en unidades de terapia intensiva y unidades de emergencia. Para colecta de datos fue utilizada una entrevista semiestructurada y un instrumento de evaluación de la ansiedad. Se destaca que fueron adoptados todos los procedimientos éticos. El estudio demostró el uso de la negación y racionalización como defensas psíquicas. Quedó evidenciada la angustia en la comunicación de la muerte del paciente y la necesidad del apoyo del servicio de psicología. Fueron sugeridas mejorías en la graduación de los cursos de enfermería y creación de espacios terapéuticos.

Palabras clave: Tanatología; Muerte; Enfermeros.

\section{INTRODUÇÃO}

\section{Apresentação}

O presente estudo pretendeu verificar qual a reação dos profissionais enfermeiros, que atuam nas unidades de terapia intensiva (UTI) ou unidades de pronto atendimento (UPA), incluído pronto socorro hospitalar, diante do processo de morrer e morte de seus pacientes. Nas palavras de Santos (2007), a morte é uma realidade muito viva e constante para aqueles que trabalham na área da saúde, notadamente nas salas de UTI e com pacientes com doenças fatais que necessitam de cuidados paliativos.

Pode-se dizer que a formação acadêmica do profissional enfermeiro é direcionada no sentido da cura da enfermidade e assistência ao paciente, não sendo esse profissional preparado na graduação para lidar com as emoções advindas do término do ciclo vital. Quando se trata do fenômeno morte, este parece estar excluído do processo vital. 
Nas diretrizes nacionais emitidas pelo Ministério da Educação, que devem ser observadas pelas Instituições de Ensino Superior dos Cursos Enfermagem, não há referência expressa sobre o fenômeno morte ou o manejo profissional depois da morte de pacientes ou luto pela perda de pacientes, ou seja, questões atinentes ao fenômeno morte não fazem parte da grade curricular mínima e obrigatória. A Resolução CNE/CES nํ 3/2001 define os princípios, fundamentos, condições e procedimentos da formação de enfermeiros; descreve o perfil do formando egresso/profissional; elenca os requisitos mínimos para dotar o profissional para o exercício da profissão nas questões relativas a atenção à saúde, tomada de decisões, comunicação, liderança, administração e gerenciamento e educação permanente. A resolução elenca ainda as competências e habilidades específicas que o profissional deve adquirir, além dos conteúdos mínimos e obrigatórios a serem abordados durante a graduação e que proporcionem a integralidade das ações no cuidar da enfermagem. É encontrada apenas uma referência sobre a habilidade específica de "cuidar da própria saúde física e mental e buscar seu bem-estar como cidadão e como enfermeiro", conforme o art. 5, inciso XXXII da Resolução CNE/CES n 3/2001.

A postura da sociedade frente ao fenômeno da morte no século XX é "dar a impressão que nada mudou, a morte não deve ser percebida" (Kovacs, 2002, p. 38). A novela de Leon Tolstoi sob o título A Morte de Ivan llitch é uma ilustração perfeita do pensamento e do comportamento da sociedade moderna diante da finitude da vida. Trata-se da narrativa do processo de morrer e de morte do personagem Ivan, que acometido de uma doença incurável, se encontra restrito ao ambiente familiar. A família silencia sobre o processo de morrer de Ivan e todos ignoram a finitude da vida. Precisamente como expõe Maria Julia Kovacs, a morte não é mais considerada um fenômeno atual, e sim um fracasso da vida. O triunfo da medicalização está em manter a doença e a morte na ignorância (Kovacs, 2002).

Traçando um paralelo entre a novela russa e o processo de morrer e de morte atualmente, pode-se dizer que tal processo está restrito aos ambientes dos hospitais. Outrora, as pessoas adoeciam e morriam no conforto de suas casas; hoje, são levadas adoecidas para os hospitais e lá morrem, às vezes, nas UTI, e muitas vezes cercadas apenas pelas equipes de saúde, quase como se o processo de morte fosse delegado. Desta forma, compreender a reação diante da morte, quais suas concepções sobre a morte e os sentimentos que a morte de um paciente desperta é importante para que possamos oferecer um adequado suporte emocional para estes profissionais.

Este trabalho parte do pressuposto que a morte é um fenômeno significativo para os que ficam, especialmente o profissional enfermeiro que se dedicou a dar assistência e prestar cuidados ao sujeito que morreu. É inevitável ao profissional enfermeiro - enquanto ser humano - não criar vínculo com seu paciente, especialmente se possui o dever de prestar assistência e cuidados a ele, pois para o cuidado com outrem se faz necessária a empatia. 


\section{Revisão da Literatura}

\section{Morte versus morrer}

O Dicionário de Psicologia da Associação Americana de Psicologia (APA) define o termo 'morte' como "cessação permanente dos processos físicos e mentais de um organismo" (Vandenbos, 2015, p. 624). Desde 1980, está em vigência nos Estados Unidos o Ato Uniforme de Determinação da Morte ${ }^{1}$, no qual a morte é definida como a cessação irreversível do funcionamento fisiológico (ou seja, funções circulatórias e respiratórias espontâneas) ou a perda irreversível do funcionamento cerebral (ou seja, morte cerebral). No Brasil, o diagnóstico da morte é regido pela Resolução n 2.173/17 do Conselho Federal de Medicina, que exige a morte encefálica. Por outro lado, o processo de morrer é definido pelo referido dicionário como perda progressiva e irreversível das funções vitais que resultam no fim da vida. Essa transição da saúde para a morte pode ser rápida ou longa, previsível ou imprevisível.

Como se pode observar morte e morrer são conceitos distintos. Morte é a partida, deixar a vida, finitude, encerramento do ciclo vital. "Morrer é incerteza: como, quando, onde? Dói? Tem sofrimento? Cada um de nós procura dentro de si essas respostas" (Nucci, 2018, p. 72).

Segundo Kovacs (2002), o medo é a resposta psicológica mais comum diante da morte. É um medo universal e que atinge a todos os seres humanos. Por vezes, é difícil diferenciar entre medo e ansiedade. Geralmente, o medo é ligado a uma causa específica, enquanto que a ansiedade é um sentimento mais difuso, sem causa aparente. Nessa lógica, poderíamos dizer que a resposta medo se relaciona com o evento morte; enquanto que a resposta ansiedade está ligada ao processo de morrer.

De acordo com Kastenbaum (1983), citado por Kovacs (2002), cada pessoa teme mais um certo aspecto da morte, razão pela qual ela deve ser considerada sob dois aspectos: a) a morte do outro (medo do abandono/separação); e b) a própria morte (consciência da própria finitude). Notese que uma das principais formas de proteção contra o medo da morte é a crença de que a morte só ocorre com o outro. Enquanto que a consciência da própria finitude é o que nos distingue dos animais.

Ao longo da história, o homem apresentou diferentes visões e representações da morte, sendo catalogadas pelo historiador Philipe Ariès (2012). As mais típicas seriam: a) a morte domada, da época medieval, o moribundo sabe que vai morrer, despede-se da família e amigos e toma as providências em vida com relação a seus despojos; b) a morte em si mesmo, onde através da morte o homem toma consciência de si mesmo e da própria existência, fortemente influenciada pela

\footnotetext{
${ }^{1}$ Tradução livre do inglês Uniform Determination of Death Act.
} 
religião, com a ideia de juízo final e o aparecimento de uso de caixões (para esconder o corpo) pois há uma preocupação com a decomposição; c) a morte do outro, com forte crença numa vida futura e medo dos mortos (período em que havia preocupação com doenças e epidemias, razão pela qual os mortos eram enterrados a certa profundidade); d) a morte interdita é a morte do século XX, quando a morte passa a ser considerada um fracasso e deve ser escondida. Adota-se a postura de poupar o moribundo e ocultar a gravidade do seu estado. A morte passa a ser um fenômeno técnico, ou seja, pela parada dos cuidados (Ariès, 2012). É transferida do lar para o hospital, fazendo surgir o imperialismo da medicina, pois é o médico quem define o que é vida e o que é morte (Kovacs, 2002).

Segundo Ariès (2012), "os homens comuns tornaram-se mudos, comportando-se como se a morte não existisse. (...) a morte é vergonhosa e motivo de silêncio é, aliás, um dos caracteres estranhos mais significativos de nosso tempo". (p. 213) Refere o autor que "os sociólogos de hoje aplicam à morte e à proibição de falar nela o exemplo dado por Freud a respeito do sexo e de seus interditos". (p. 213) A morte é um tabu em nossa sociedade. "O homem deve morrer na ignorância de sua morte". (p. 213)

\section{Os profissionais enfermeiros diante da morte}

Os profissionais enfermeiros, especialmente aqueles que trabalham no contexto hospitalar, se deparam diariamente com o processo de morrer e a morte. Entretanto, dentre os objetivos principais da formação destes profissionais não consta a preparação para perdas, pelo contrário, estes profissionais são formados para curar doenças e vencer a morte. Nesse sentido, o contato dos profissionais enfermeiros com esta finitude pode provocar reações que fogem da prática técnica e profissional, impedindo que o processo ocorra de forma natural (Magalhães \& Melo, 2015).

"A diferença básica entre as pessoas em geral e os profissionais da área de saúde, médicos, enfermeiras e psicólogos é que na vida destes, a morte faz parte do cotidiano e pode se tornar sua companheira de trabalho diária. Toda doença é uma ameaça à vida e, portanto, pode aparecer como um aceno à morte." (Kovacs, 2002, p. 226)

A ampla cultura de negação da morte são fatores que favorecem repercussões negativas nos profissionais da saúde, pois a finitude do outro provoca em si um desligamento das próprias emoções. Assim, entender a morte como parte natural do ciclo vital (e não um fracasso, inclusive profissional), aceitá-la e auxiliar o próprio paciente e seus familiares nesse processo, pode influenciar positivamente a prática do profissional enfermeiro, prevenindo doenças psíquicas (Magalhães \& Melo, 2015).

O profissional qualificado para o exercício da enfermagem deve "incorporar a ciência/arte do cuidar como instrumento de interpretação profissional” (art. 5ํ, inciso II da Resolução CNE/CES no 
3/2001) devendo pautar seu exercício profissional pela educação permanente. Se este profissional pode/deve cuidar da vida, pode/deve cuidar da morte também. Nesse sentido, o profissional enfermeiro para cuidar da vida, deve ser educado para cuidar da morte, contribuindo para uma melhor elaboração do luto. Segundo Nelly A. G. Nucci, "a articulação entre cuidar e educar para a vida e a para morte deve ser a estrutura da qual se origina o desenvolvimento profissional em saúde integral" (Nucci, 2018, p. 66).

Nesse sentido, o profissional de enfermagem não deve entender a recusa de tratamento pelo paciente como um ataque pessoal, mas sim como vontade desse sujeito que deseja morrer em paz. O profissional deve evitar agir com desprezo (Kovacs, 2018).

\section{Os sentimentos despertados pela morte}

O Dicionário de Psicologia da APA define 'emoção' como um “padrão de reação complexo, envolvendo elementos experimentais, comportamentais e fisiológicos, pelo qual um indivíduo tenta lidar com um assunto ou evento pessoalmente significativo" (Vandenbos, 2015, p. 334). O mesmo dicionário traz 'sentimento' como "experiência fenomênica completa". Desta forma, podemos dizer de maneira singela que a emoção seria a reação química e neural diante de um estímulo, ao passo que o sentimento seria a interpretação dada pelo indivíduo àquela reação. Então, a emoção se relaciona com o mundo interno e externo, enquanto que o sentimento apenas com o mundo interno. A emoção é a resposta interna (reação) dada a um estímulo externo (evento). E o sentimento é resposta interna (e subjetiva) dada a um estímulo também interno (emoção). A título de ilustração, podemos descrever a emoção como o batimento cardíaco acelerado (reação química) diante de uma situação específica e o sentimento como irritação.

Embora, emoção e sentimento se confundam no senso comum, nosso objetivo é falar sobre a capacidade de identificar emoções e sentimentos, ou seja, da habilidade que Daniel Goleman (1995) chama de inteligência emocional. É fundamental que os profissionais da saúde tenham a capacidade de identificar suas próprias emoções e sentimentos quando diante do fenômeno morte. Desenvolver tal habilidade emocional permite ao profissional enfermeiro manter sua saúde mental equilibrada, além de influenciar positivamente o seu paciente. Saber interpretar as suas emoções e sentimentos, permite aceitar a vontade/desejo do paciente que está no processo de morrer de maneira saudável.

Elizabeth Kübler-Ross (2003) refere que devemos respeitar nossas emoções naturais. Significa dizer que não devemos transformar essas emoções em algo não natural. A autora afirma que a síndrome da explosão ocorre quando transformamos emoções naturais em não naturais e reprimimos nossos afetos. Inclusive exemplifica a situação com um profissional de saúde trabalhador de uma UTI. No exemplo, Kübler-Ross (2003) traz a cena hipotética do profissional que 
está a uma hora de sair do seu turno, quando recebe um sexto paciente na UTI. A frustração do profissional em saber que seu turno se prolongará é reprimida, pois esses profissionais são treinados a manterem-se calmos e sorridentes. A explosão pode acontecer depois, ou, caso não ocorra, levará o profissional a um esgotamento físico-mental (Kübler-Ross, 2003).

Conforme expõe Kübler-Ross, transformar as emoções em não naturais equivale a reprimir seus sentimentos com relação ao processo de morrer e de morte, quando o paciente expressa seu desejo de morrer materializado numa diretiva antecipada de vontade (DAV) [desejo], o que pode gerar profunda frustração ao profissional diante da sua impotência com o avanço da doença que culminará com a morte. Assim, é importante a investigação desses sentimentos para ajudar no desenvolvimento da habilidade emocional desses profissionais.

\section{Estudos Encontrados Nos Últimos Cinco Anos}

a) Magalhães e Melo (2015) apresentaram estudo que teve como objetivo evidenciar as dificuldades encontradas por profissionais da saúde em lidar com a morte e o luto na sua prática profissional e apresentar capacidade de reflexão sobre ações para minimizar seu sofrimento diante do binômio vida e morte. Tratou-se de pesquisa exploratória de revisão de literatura que apontou a necessidade da revisão da formação acadêmica dos profissionais da saúde e da divulgação de informações sobre estratégias de enfrentamento diante do processo de morte e luto.

b) Sancho Pereira Neto, Nunes Caixeta, Soares Melo, e Antoniassi Junior (2019) fizeram estudo de campo exploratório com profissionais da enfermagem com objetivo de conhecer as experiências vivenciadas nas UTI e como esses profissionais lidam com a morte. Seus achados apontaram a necessidade de acompanhamento psicológico para os enfermeiros atuantes nas UTI, bem como sugeriram maior investimento nas grades curriculares que permitam a preparação do acadêmico para a vivência dentro do âmbito hospitalar, permitindo assim discussões sobre a temática da morte e do morrer de pacientes.

c) Oliveira, Felipe, Barbosa, Santos e Viana (2020) apresentaram estudo no sentido de comprovar que o profissional enfermeiro necessita de suporte emocional e psicológico, tanto quanto o paciente e familiares diante da morte. Tratou-se de estudo de revisão integrativa junto a base de dados LILACS no período de 2013 a 2017, sendo utilizado os subscritores morte, enfermeiro, emoção e tanatologia. O estudo concluiu pela necessidade de trabalhar o emocional dos profissionais.

Como se pode verificar, todos os estudos apontaram a necessidade de suporte emocional aos profissionais. Contudo, é imprescindível conhecer quais são as reações e sentimentos despertados pela morte para um adequado suporte emocional a esses profissionais, no sentido de verificar as ideias, percepções e discurso dos próprios profissionais a respeito do fenômeno morte. 


\section{MATERIAIS E MÉTODOS}

\section{Delineamento}

Trata-se de um estudo de caso múltiplo, qualitativo, de cunho exploratório. A abordagem qualitativa sugere uma relação entre o mundo real (morte) e o sujeito, pois identifica e analisa dados não mensuráveis (emoções, sentimentos, valores, representações, etc). Entende-se por pesquisa exploratória aquela que visa proporcionar maior familiaridade com o fato ou fenômeno, a fim de torná-la mais clara, objetivando o aprimoramento de ideias. Seu planejamento é flexível de maneira a valorar de diversas maneiras o fato estudado (Selltiz et al., 1967, como citado em Gil, 2002, p. 41). E, nas palavras de Yin (2015), o estudo de caso múltiplo é uma investigação empírica de um fenômeno contemporâneo dentro de um contexto da vida real (local de trabalho do profissional enfermeiro), sendo que os limites entre o fenômeno (morte) e o contexto não estão claramente definidos (emoções advindas do enfrentamento do processo de morte e do morrer de pacientes).

\section{Participantes}

Participaram deste estudo dezesseis profissionais enfermeiros, por meio de convite efetuado por e-mail, whatsapp e/ou redes sociais. Sendo inclusos aqueles enfermeiros que concordaram em participar da pesquisa, com registro ativo no COREN, com experiência mínima de seis meses em Unidades de Terapia Intensiva (UTI), Unidades de Pronto Atendimento (UPA) ou Pronto Socorro hospitalar. E exclusos aqueles que não atenderam os critérios de inclusão e/ou não assinaram o Termo de Consentimento Livre e Esclarecido. Foi garantido a todos o sigilo das informações e anonimato às respostas. As entrevistas foram gravadas em mídia digital com o conhecimento dos profissionais.

\section{Instrumentos}

(1) Entrevista semiestruturada - roteiro desenvolvido pela proponente da pesquisa que busca investigar concepções sobre a morte, reação diante da morte, sentimentos em relação à morte. Na primeira parte, constou dados de identificação (sexo, idade, local de trabalho, turno de trabalho, tempo de profissão, tempo de experiência na unidade, nível de escolaridade, religião). Na segunda parte, três perguntas fechadas sobre tanatologia, seis perguntas abertas relacionadas à morte e seus significados e sentimentos despertados.

(2) Escala de Ansiedade Perante a Morte (DAS) - é uma escala breve constituída por um total de 15 itens, 9 formulados na forma positiva (itens $1,4,8,9,10,11,12,13,14$ ) e 6 formulados 
na negativa (itens $2,3,5,6,7,15)$. É uma escala do tipo likert de 5 pontos que varia entre Concordo Plenamente e Discordo Plenamente, o score máximo possível é de 75 pontos e o mínimo é de 15, quanto maior for o score obtido maior será ansiedade perante a morte, sendo a pontuação dividida seguinte forma: 15 a 35 pontos, ansiedade leve ou baixa; 36 a 55 pontos, ansiedade moderada; e 56 a 75 pontos, ansiedade alta ou grave.

\section{Procedimentos Éticos}

Esta pesquisa foi realizada considerando a Resolução $n^{\circ} 466 / 2012$ e a Resolução $n^{\circ}$ 510/2016 do Conselho Nacional de Saúde (CNS), que regulamenta a pesquisa com seres humanos. O projeto de pesquisa foi submetido ao Comitê de Ética da Universidade de Passo Fundo (UPF) sendo aprovado pelo Parecer o 4.571.313, em 03 de março de 2.021 (CAEE 40598220.5.0000.5342). Os dados dos participantes serão mantidos em sigilo e toda a documentação oriunda da pesquisa será devidamente guardada em local protegido, conforme a legislação. Os instrumentos deste estudo apresentam risco mínimo aos seus participantes.

\section{Entraves à Realização da Pesquisa e Procedimento para Coleta e Dados}

Depois de aprovado o projeto pelo Comitê de Ética, foram contatadas as Instituições Hospitalares através do setor de Recursos Humanos a fim de convidar os enfermeiros interessados a participar da pesquisa. Entretanto, em razão do agravamento da pandemia de Covid 19 (bandeira preta no modelo de distanciamento controlado adotado pelo Governo do Estado do Rio Grande do Sul), não houve adesão das instituições hospitalares, cujas autorizações foram inicialmente colhidas, uma vez que todos os recursos disponíveis foram utilizados no combate da epidemia, bem como alguns dos profissionais contatados foram acometidos pelo Covid e/ou ante a alta demanda de pacientes não possuíam tempo disponível para a participação na pesquisa, razão pela qual foi aberta a possibilidade de participação a qualquer profissional enfermeiro com registro no COREN e com no mínimo seis meses de experiência em UTI, UPA ou Pronto Socorro Hospitalar, e que concordassem com o Termo de Consentimento Livre e Esclarecido. Assim, os participantes foram convidados a partir de divulgação em redes sociais, grupos de whatsapp, via e-mail ou telefone. Desta forma, houve a participação de enfermeiros de quatro hospitais da região noroeste do Rio Grande do Sul e dois hospitais da cidade de Curitiba, Paraná.

O Termo de Consentimento Livre e Esclarecido e o Instrumento Escala de Ansiedade Perante a Morte foram coletados por via digital, sendo todas as entrevistas realizadas por chamada de vídeo, com criptografia de ponta a ponta de maneira a manter o sigilo das respostas dos participantes, conforme a disponibilidade de horário dos profissionais. Todos os profissionais 
participaram da pesquisa de forma voluntária, sendo que as entrevistas foram realizadas depois de enviado o TCLE devidamente assinado e do preenchimento da escala.

\section{Análise de Dados}

Os dados coletados mediante entrevista foram analisados seguindo-se a fundamentação teórica da análise de discurso, cada vez mais utilizada na Psicologia Social. Cada caso será analisado de acordo com o sentido produzido a partir da posição do sujeito (enfermeiro), contexto sócio-histórico e linguagem. Pretendeu-se verificar quais os sentidos pré-constituídos sobre o fenômeno morte, analisando-se a relação entre o interdiscurso (memória coletiva) e o intradiscurso (fala), de modo a compreender o sentido do discurso produzido, partindo-se de uma premissa de que esse profissional é também assujeitado ao coletivo de sua categoria profissional, ainda que de forma inconsciente.

\section{RESULTADOS E DISCUSSÃO}

\section{Os Dados Sociodemográficos}

A amostra é composta por dezesseis profissionais $(n=16)$, sendo $81,25 \%$ do sexo feminino e $18,70 \%$ do sexo masculino. Com relação ao nível escolaridade, temos $31,25 \%$ com graduação, $62,50 \%$ com um ou mais cursos de especialização lato sensu ou MBA, e 6,25\% com doutorado. Com relação à religiosidade, $68,75 \%$ se declarou católica, $12,50 \%$ protestantes, $12,5 \%$ espíritas e $6,25 \%$ sem religião definida. A média de idade dos profissionais por ocasião da coleta de dados era de 36 anos, sendo que o profissional mais jovem tinha 23 anos de idade e o mais velho 47 anos. Com relação ao tempo de profissão como enfermeiros, a média era de 9,5 anos, sendo que o menor tempo registrado foi de 10 meses e o maior de 22 anos. Quanto ao tempo de experiência em UTI, UPA ou Pronto Socorro hospitalar, a média era de 4 anos, sendo o menor tempo 7 meses e o maior tempo 18 anos. Ainda, 50\% trabalham em UTI Geral, 31,25\% trabalham em UTI Covid, 12,50\% em Pronto Socorro hospitalar e 6,25\% em UTI Neonatal. E também 56,25\% da amostra declarou trabalhar no período diurno, enquanto que $43,75 \%$ declarou trabalhar em período noturno. Por fim, $68,75 \%$ sabem o que é tanatologia, enquanto $31,25 \%$ não sabem. Daqueles que sabem o que é tanatologia, $63 \%$ nunca leram ou tiveram qualquer contato com esse tipo de estudo.

Rev. Psicol Saúde e Debate. Jan., 2022:8(1): 74-96. 


\section{A Escala de Ansiedade Perante à Morte (DAS)}

A aplicação deste instrumento ocorreu de forma remota, ou seja, não foi possível observar as reações dos participantes ao lerem as perguntas, embora alguns poucos tenham relatado ficar impactados e mais pensativos sobre a morte, "pois não é um assunto que pensamos normalmente" (Enfermeira 2). O documento foi enviado por meio eletrônico a cada um dos participantes e preenchidos individualmente antes de realizada a entrevista. Será considerado apenas o resultado geral, não sendo objeto deste estudo a análise e quantificação de cada item da escala. Todos os participantes apresentaram durante o período da coleta de dados ansiedade moderada. Ou seja, com pontuação entre 36 e 55 pontos.

Isso significa que a qualidade de vida desses profissionais requer, no mínimo, atenção. Sentir ansiedade leve é normal, todos nós sentimos ansiedade, pode ser considerada uma resposta do organismo. A ansiedade pode refletir um traço de personalidade ou um estado ansioso provocado por uma determinada situação externa. Considerando que todos esses profissionais exercem suas atribuições em setores de emergência e urgência, é necessário salientar que a manutenção de um estado ansioso por um período prolongado de tempo pode gerar prejuízos na atenção seletiva.

Segundo Sadock e Sadock (2007):

“(...) a ansiedade afeta o pensamento, a percepção e o aprendizado. Tende a produzir confusão e distorções da percepção, não apenas do tempo e do espaço, mas também das pessoas e dos significados dos acontecimentos. Essas distorções podem interferir no aprendizado ao diminuir a concentração, reduzir a memória e perturbar a capacidade de fazer relações." (p. 632)

No mesmo sentido, Cassorla (2015):

"A ansiedade é um afeto normal e com importante função homeostática. A diferença entre a ansiedade normal e a patológica é tênue. Em relação ao segundo tipo, com frequência o organismo manifesta a ansiedade com maior intensidade do que a necessária para a tarefa em questão, ou a situação é tão traumática que a ansiedade não é contida pelo self. (...) Quando a ansiedade aumenta e irrompe de forma abrupta, engolfa o indivíduo, tornando-o aterrorizado e impotente, bloqueando sua capacidade de pensar." (p. 493)

Dois pontos importantes devem ser levados em consideração em relação ao resultado apresentado pelos profissionais. Primeiro, os dados foram coletados em um dos piores momentos da pandemia de Covid no Brasil. Os enfermeiros são os chefes de equipes, logo, também responsáveis pelo gerenciamento dos recursos da unidade, um fato que pode ser considerado também estressor, além do próprio ambiente de urgência e do momento histórico da pandemia. Segundo muitos profissionais relataram nas entrevistas, as afirmativas da escala eram impactantes.

Rev. Psicol Saúde e Debate. Jan., 2022:8(1): 74-96. 
Contudo, optaram por permanecer neutros em suas respostas, pois "precisam" manter o equilíbrio. Ou seja, o dever com a equipe e a postura profissional sempre é prioridade, mascarando eventuais sentimentos despertados ali. Como se não lhes fosse permitido vivenciar os próprios sentimentos. Isso aponta para um mecanismo de defesa conhecido como negação, no qual os pensamentos ou emoções são ignorados ou excluídos da atenção consciente. Geralmente utilizado para minimizar conflitos internos e reduzir a ansiedade, uma forma através da qual o mecanismo psíquico busca sua homeostase.

\section{As Entrevistas}

Os dados obtidos foram categorizados a partir das respostas, conforme a semelhança no discurso, em quatro categorias: (I) significados da morte no discurso profissional; (II) representações e sentimentos despertados - o discurso sobre os tipos de morte; (III) reação em relação à morte $\mathrm{e}$ as formas de transferência evidenciadas no discurso profissional; e (IV) sentimentos relacionados à própria morte.

\section{Categoria I - Significados da Morte no Discurso Profissional}

No que diz respeito aos significados da morte, foram identificados dois discursos: (a) a morte como fim de um ciclo vital e com fim da existência, numa perspectiva meramente biológica, e (b) a morte como fim de um ciclo vital, meramente físico, mas com início de uma vida espiritual.

O Fim Meramente Biológico. É marcado no discurso dos profissionais o significado da morte como algo meramente biológico, racional e concreto. O significado de morte é remetido a algo meramente técnico, um ciclo vital que se encerra, um processo cotidiano de nascer, crescer, se desenvolver (realizando alguns objetivos como casar, ter filhos, adquirir bens), envelhecer e morrer.

Algumas das falas:

"A morte é o final de um ciclo." (Enfermeira 9)

"A morte é o fim da existência, de tudo que construímos." (Enfermeira 1)

"A morte é o fim de um ciclo. A morte é o acabar de tudo." (Enfermeiro 15)

"A morte para mim é o fim da vida. Morreu, acabou." (Enfermeira 2)

"A morte é o final dos sinais vitais, o fim da vida". (Enfermeira 13)

Embora possa parecer natural ver a morte como parte de um ciclo, encarar a finitude da vida, transformando-a em algo cotidiano e concreto, além de mostrar que a morte está em sua rotina, também sugere outra interpretação do discurso: uma defesa psíquica. No sentido de que 
objetificar tal processo, torna o real mais concreto, mensurável. Segundo Laplanche e Pontalis (2016) a racionalização é um processo pelo qual o sujeito procura apresentar uma explicação lógica ou aceitável para um fato, um processo usado para se defender de sentimentos de culpa ou crítica. Uma vez que é um fenômeno corriqueiro nas UTIs ou pronto socorro o fenômeno morte, agregar a ela um significado técnico, a torna suportável e a mantém a certa distância.

Um fato curioso identificado é que os profissionais das falas acima descritas são aqueles com maior tempo de profissão (acima de dez anos), maior experiência em UTI ou Pronto Socorro hospitalar (acima de cinco anos), que trabalham no período noturno, e não possuem conhecimentos sobre tanatologia. E também refletem as falas dos profissionais com menor tempo de profissão (menos de dois anos) e também menor experiência em UTI ou Pronto Socorro Hospital (menos de dois anos).

Nesse sentido, poderíamos pensar que a experiência profissional por si só não é suficiente para que os profissionais "aprendam a lidar" com a morte em seu cotidiano. E que esse aprendizado perpassa por um conjunto de fatores. Tanto relacionado aos traços de personalidade e biológicos (são pessoas diurnas ou noturnas), quanto a continuidade dos estudos acadêmicos (conhecimento em Tanatologia, o estudo da morte).

Os profissionais que têm maior experiência profissional, talvez estejam em um ambiente adverso que paulatinamente vai deteriorando sua saúde mental, ainda que conscientemente acreditem que tal ambiente não lhes represente risco. Talvez seja necessário trazer a discussão que não só o ambiente físico é insalubre e apresenta risco numa UTI, mas que o excesso de mortes nestas unidades é tão nocivo para a saúde mental da equipe de trabalhadores, quanto uma bactéria resistente ou um vírus para o qual não se tenha a cura. E talvez, seja necessário se ter um tempo limite para permanecer nessas equipes de trabalho, sendo essencial um acompanhamento terapêutico a cada um deles.

O Fim da Existência Física e Início da Vida Espiritual. Outros profissionais, embora também filiados ao discurso técnico, cuja morte significa o fim de um ciclo vital, agregam ao discurso uma visão pessoal influenciada pela religiosidade, acreditam que há uma continuidade da vida na forma espiritual.

Algumas falas:

"A morte para mim é uma mudança de ciclo. Eu acredito muito que a gente morre e vai para uma outra vida." (Enfermeira 7)

"Eu acredito que seja o encerramento de um ciclo, mas não que seja o fim, o término de tudo." (Enfermeira 11)

"A morte para mim significa uma continuidade. Não termina aqui." (Enfermeira 10)

"Acho que a morte é uma reciclagem. Entendo que a religião complementa a ciência. Não sei o que acontece depois, mas acho que é o fim de um ciclo e o início de outro." (Enfermeiro 16) 
"Eu acho que é o encerramento de um ciclo, mas eu acredito em vida após a morte." (Enfermeira 3)

"Morte pra mim é uma transição, uma passagem desta vida carnal para uma espiritual." (Enfermeira 4)

Note-se que a religiosidade presente no discurso atua como um "instrumento de proteção e explicação perante os acontecimentos difíceis" (o fenômeno morte), o mesmo achado segundo Ribeiro, Baraldi e Silva (1998, p.120) quando investigaram a percepção da equipe de enfermagem no ritual de preparo do corpo pós-morte.

No mesmo sentido Oliveira et al. (2020):

“... a força da espiritualidade pode ser vista como um instrumento de promoção da saúde na medida em que lida com as dimensões pouco conscientes do ser, cujos embasamento envolvem os valores, as motivações no sentido da existência individual e coletiva das pessoas." (p. 4569)

Em relação a esses profissionais, não passou despercebido que trabalham em turno diurno, já tiveram aulas ou fizeram leitura sobre temas de tanatologia, mencionaram durante as entrevistas fazer acompanhamento terapêutico com psicólogo, mencionaram perder pessoas próximas do núcleo familiar de forma precoce (infância ou adolescência) ou recentemente (por Covid ou outras causas).

Os profissionais que demonstram uma forte espiritualidade parecem encontrar um propósito maior e um sentido. Além dessa virtude parecem ter uma atitude mais positiva para com a vida, o que também se observa empiricamente em pessoas diurnas. $E$ as experiências pessoais de perdas familiares e acompanhamento terapêutico com psicólogo também contribuem para adentrarmos em outro processo de nos colocarmos no mundo e, consequentemente, enfrentarmos as adversidades. Alguns poderiam dizer que são fatores que contribuem para uma maior resiliência.

\section{Categoria II - Representações e Sentimentos Despertados - O Discurso Sobre os Tipos de Morte}

Vivemos a era da morte interdita como já mencionado, conforme descreve Ariès (2012), cujo desejo é evitar falar da morte não só para "poupar" o moribundo, mas também evitar a perturbação e a emoção excessivamente fortes, insuportáveis, "causadas pela simples presença da morte em plena vida feliz, pois a partir de então, admite-se que a vida é sempre feliz, ou deve sempre aparentá-lo." (p. 85).

Segundo Alencar, Lacerda e Centa (2005, p. 178), "quando alguém morre em um hospital, o corpo é rapidamente retirado do local para não chocar as pessoas, pois nesse ambiente os pacientes não morrem: expiram." A fala da Enfermeira 3 ilustra bem esse comportamento em que é necessário esconder a morte:

Rev. Psicol Saúde e Debate. Jan., 2022:8(1): 74-96. 
"É muito difícil falar da morte... e a gente vê que a gente tem muita dificuldade para falar sobre isso, tanto que a gente não tem regra quando dá um óbito... a gente segue os protocolos da instituição, mas cada óbito é diferencial e a gente reage diferente. Eu tento passar para a equipe que se tá difícil, vamos respirar... mas a gente não pode se desequilibrar né, o equilíbrio a gente precisa manter porquê do ladinho desse paciente que faleceu agora, tenho paciente lúcido, ouvindo, escutando tudo, entendendo o que tá acontecendo." (Enfermeira 3)

A representação da morte do outro é confundida com as emoções e os sentimentos despertados pelo fenômeno morte em si. Descreveram sentimentos negativos, dizendo que a morte representa perda, tristeza, dor e sofrimento, tanto para si enquanto profissionais, quanto para os familiares. E também sentimentos positivos de paz, alívio e completude do ciclo vital. Um discurso muito frequentemente remetido ao uso do pronome indefinido "alguém", denotando impessoalidade, como se quisessem colocar ali uma barreira emocional e/ou tratar o sujeito que morre como um isso (objeto), não é uma morte, mas apenas um óbito.

"Todo paciente é o amor de alguém, o familiar de alguém, a gente cita bastante isso, não vou dizer que a gente não sente ou não sofre, mas é uma perda principalmente para a família, mas também uma perda para nós. Às vezes, uma frustração de não conseguir ter feito tudo para poder salvar, enfim, mas não deixa de ser um sofrimento e um pedacinho da gente que vai junto." (Enfermeiro 15)

Com relação ao tipo de morte, a morte súbita de jovens, especialmente em razão de acidentes automobilísticos (trauma) ou arma de fogo (relacionada à criminalidade) e também de bebês ou crianças são mais difíceis. Segundo Shimizu (2007, p. 260), "a idade parece ser a característica mais expressiva, pois representa a potencialidade que uma pessoa tem para contribuir para a sociedade". Nesse sentido, devemos considerar o contexto sócio-histórico dos participantes, enquanto indivíduos inseridos em uma sociedade movida pelo capital, que, em última análise, contribui para o tabu em relação à morte, uma vez que velhos ou mortos são corpos que não mais produzem.

Algumas falas:

"Quando são jovens abala mais. A gente fica mais abalado, mas quando é um idoso, a gente entende." (Enfermeira 9)

"A morte é uma coisa impactante. Quando é muito jovem a gente fica naquele processo de negação, de não aceitar, que é diferente quando é uma pessoa idosa." (Enfermeiro 16) 
Outros termos frequentemente utilizados no discurso dos profissionais para caracterizar o tipo de morte, não dizia respeito apenas a idade do paciente, mas também a condição de saúde, no sentido de ser uma morte inesperada. Segundo Mattos et al. (2009, p. 340), "morte inesperada é aquela em que o paciente tem um bom prognóstico de recuperação, está bem, e, de repente, morre, acontece uma intercorrência - por exemplo, uma parada cardíaca -, e acaba morrendo". A morte inesperada é também de difícil aceitação pelos profissionais. Esse tipo de morte ficou muito evidente no discurso em razão da pandemia, que será retomada na última categoria.

"Quando vejo a morte de alguém muito jovem, que tem muitos sonhos, eu vejo com tristeza e o que me conforta é que tem a vida eterna. Quando eu vejo a morte de um idoso, que está acamado, que não anda, que a família já está esgotada, eu vejo como um alívio. Depende da idade e da condição do paciente. Um fato que mexeu muito comigo, por exemplo, foi um paciente bem jovem, vinte e poucos anos que foi baleado devido a uma questão envolvendo droga. Ele era um paciente bem vestido e bem cuidado. $E$ aquilo mexeu. $E$ ainda mais quando a mãe entrou na emergência com ele em óbito. E outro paciente, que era bem idoso e estava muito tempo entubado e vi como um conforto pra ele." (Enfermeira 10)

Algo que chama a atenção quando os profissionais falam sobre os tipos de mortes e tipos de pacientes é a omissão dos pacientes que tentaram suicídio. É sabido que, além de um despreparo para lidar com comportamento suicida, há também um menosprezo dos profissionais da saúde pelas pessoas que se auto lesionam, uma vez que como já dito anteriormente os profissionais da saúde são treinados para salvar vidas. Botega (2015) em seu livro clássico Crise Suicida Avaliação e Manejo, traz falas de profissionais da saúde do Hospital de Clínicas da Unicamp antes de ser realizado um grupo operativo sobre a prevenção do suicídio: "Tanta gente esperando vaga, querendo viver, e aquele lá, que tentou se matar, ocupando um leito tão precioso de UTI. [...] Dá vontade de dizer, da próxima vez se mata mesmo! Dá um tiro na cabeça!" (p. 28). Existem vários estudos que concluem nesse sentido, sem correr o risco de generalizações. E a maioria dos profissionais entrevistados trabalha em municípios com alto índice de suicídios. A omissão desse tipo de morte também revela a negação da morte.

É cultural pensar que suicídio ou morte são assuntos mórbidos. E ninguém quer pensar, muito menos falar nesses assuntos, pois nos obriga a encarar a própria finitude. Embora os profissionais queiram imprimir ao seu discurso o sentido de que a morte é natural e faz parte do ciclo da vida, o que está por trás do discurso é uma negação coletiva, a principal estratégia de confronto com a realidade do ambiente. Diferenciar o tipo de morte pela condição de saúde também pode ser considerada uma estratégia para o enfrentamento desta realidade permeada de mortes constantes, uma vez que o profissional vê conforto no alívio da dor do outro.

Rev. Psicol Saúde e Debate. Jan., 2022:8(1): 74-96. 


\section{Categoria III - Reação em Relação à Morte e as Formas de Transferência Evidenciadas no Discurso Profissional}

Segundo Sancho Pereira Neto et al. (2019, p. 7), "os profissionais de enfermagem atuantes de unidades de terapia intensivas estão expostos a mortes e perdas frequentes", o que foi corroborado pelos participantes desse estudo. Veja a fala da Enfermeira 2:

"Ah, depende, a gente lida muito com morte, com os pacientes que morrem, aí vai depender de várias coisas, se eu conheci antes esse paciente ou não, porque, às vezes, o paciente chega inconsciente, entubado. Outras, chega conversando e te conta várias coisas que depois a gente vai alimentando..." (Enfermeira 2)

Entretanto, não foi constatada uma reação de evitação no contato com os pacientes em si, pelo contrário. Como fica evidenciado na fala acima, muitos pacientes já chegam até inconscientes, não sendo possível qualquer interação ou estabelecimento de qualquer vínculo ou transferência. Entendida a transferência aqui não apenas no sentido psicanalítico, mas universal. A fala da Enfermeira 3, a seguir, demonstra que quanto menor o contato com o paciente ou seus familiares, menor o sofrimento com a perda do paciente:

"Tem toda uma questão de vínculo porque no turno da manhã é o horário de visita, então tu vai criando um vínculo com essa família, toda manhã. Então, eu já senti que depende do vínculo que a gente tem com aquela família. A gente reage ao óbito dependendo do vínculo. Eu já presenciei óbitos que eu não tinha tanto contato e foi mais tranquilo, a gente não sofre tanto." (Enfermeira 3)

Para a grande maioria dos profissionais, é também o contato com a família que vai influenciar a reação ao óbito do paciente. Sendo que a principal questão levantada pelos profissionais e que denota motivo de grande angústia é a comunicação da morte do paciente para a família. Dos profissionais entrevistados, $25 \%$ trabalha em hospitais que não contam com suporte de serviço de psicologia ou profissional psicólogo na equipe de trabalho. Exemplos:

\footnotetext{
"Algo que eu penso é que por mais que você estude ou pensa que esteja preparado, nós profissionais da saúde nunca estamos preparados para a morte. Para dar a notícia. (...) Um serviço de psicologia faz muita falta." (Enfermeira 13)

"(...) parece que a gente esfria e começa a pensar que a gente vai ter que conversar com a família e explicar o que aconteceu. Eu vejo que o pior não é em relação a morte do paciente em si, mas o que deixa a gente mal é em relação a família (...) porque a gente conta e encaminha eles para verem o seu ente." (Enfermeiro 15)
}

Ainda aqueles que contavam com o auxílio do profissional psicólogo, relatam que a notícia para a família era algo difícil, conforme as falas abaixo: 
“... acho que não morreu com dor, eu sempre penso isso. E penso na família... de dar essa notícia, sabe? Não é a gente que dá, mas tu participa do processo ali. Então, eu acho bem difícil isso (...), eu penso na notícia para a família." (Enfermeira 14)

"(...) quando acontece o óbito o pessoal entra num desespero... precisa fugir, sabe? Daí a recepcionista liga para avisar que a família chegou, daí, meu Deus, do céu, e agora quem vai conversar? Tipo assim, eu não! Não é uma coisa que a gente não quer, mas se sente totalmente desconfortável. Daí eu falo: manda a família subir, a gente vai junto, o médico vai junto e tem o psicólogo - Graças a Deus!" (Enfermeiro 16)

Considerando que a negação da morte é muito forte na nossa cultura e no ambiente hospitalar, não foram relatados sentimentos de impotência ou culpa em relação à morte dos pacientes. Aliás, a maioria dos entrevistados demonstrou segurança em relação aos seus conhecimentos técnicos, não questionando suas habilidades profissionais pelo desfecho morte. A maior angústia com relação a perda de um paciente é a comunicação da morte para a família. É inegável que o profissional sinta a morte, o sentimento de perda e tristeza que o fenômeno invoca, contudo manejar as próprias emoções e também saber como manejar as emoções dos familiares no momento de comunicar a notícia da morte é uma situação que parece ir além do desconforto, uma verdadeira sobrecarga emocional para a qual os profissionais não se sentem preparados. Foi unânime, entre todos, a necessidade de um profissional psicólogo na equipe do hospital. E aqueles que não tinham esse suporte, demonstraram maior sofrimento psíquico em suas falas.

Assim, não bastam profissionais tecnicamente preparados, é preciso investir também em profissionais emocionalmente preparados, pois essa sobrecarga emocional a longo prazo pode levar a um desequilíbrio da saúde mental do profissional. Como já foi dito, é necessário trazer à discussão formas de promover esse cuidado, seja estabelecendo-se um tempo limite para atuar nos setores de urgência e emergência, seja promovendo o acolhimento terapêutico desses profissionais com um serviço de psicologia voltado para esses profissionais, ou ainda, educando também para a morte nos bancos acadêmicos para que sejam promovidas reflexões sobre o processo de morte e morrer.

\section{Categoria IV - Sentimentos Relacionados à Própria Morte e o Covid}

Enfrentar a morte é uma experiência subjetiva de cada um de acordo com o momento em que estamos vivendo. A nossa idade atual, se já vivenciamos a parentalidade, já vivenciamos o luto de algum familiar do núcleo mais próximo, tal como mãe, pai ou irmão. Quando o enfermeiro enfrenta a morte de um paciente da mesma idade dele a finitude se apresenta de maneira mais concreta. Quando enfrenta a morte de algum paciente, cuja idade é próxima a dos filhos, o processo de identificação também é imediato, e a situação causa maior sensibilidade. E por fim, aqueles enfermeiros que já vivenciaram o luto pela perda de um familiar, parecem se colocar mais próximos tanto do paciente em estado terminal quanto dos familiares.

Rev. Psicol Saúde e Debate. Jan., 2022:8(1): 74-96. 
Nesse contexto, uma estratégia de enfrentamento para lidar com a própria finitude é o discurso de separar as emoções vividas no trabalho da vida fora do trabalho. Esse "lidar profissionalmente" com a questão fazendo uma cisão nas emoções nada mais é que um mecanismo de defesa para suportar o cotidiano. Um verdadeiro arranjo mental do aparelho psíquico para suportar o desgaste emocional.

Veja a fala abaixo:

"(...) se tu vai se apegar, profissionalmente falando, tu acaba se desgastando. Não pode levar para casa aquilo que tu tava vivendo lá. (...) Para mim é bem tranquilo, eu consigo sair do meu âmbito de trabalho profissional, e voltar para a minha casa sem levar isso junto." (Enfermeira 14)

Como dito anteriormente, a morte inesperada, aquela em que o paciente tem um bom prognóstico de recuperação e acaba morrendo, é de difícil aceitação pelos profissionais. Isso porque, talvez, a maioria dos pacientes são graves e não têm bons prognósticos, logo, a probabilidade da morte é sempre mais alta nas unidades de urgência e emergência. A pandemia de Covid no entanto, bagunçou um pouco essa lógica.

Eis algumas falas dos profissionais:

"O paciente de Covid é muito cruel! O paciente tá falando, tá lúcido e a gente tem que entubar ele porque o pulmão tá horrível, então tem toda essa parte da despedida... acho que foi o pior momento da pandemia (...) é muito estressante e pode acontecer várias coisas no momento em que tu vai entubar um paciente, toda a equipe fica estressada, tu nunca sabe o que vai acontecer... a pressão psicológica é muito grande porque o paciente desestabiliza muito rápido! Emocionalmente é muito difícil! (...) antes de a pessoa ser entubada, a gente faz vídeo chamada... é muito difícil... já presenciei uma mãe falando com duas filhas e dando orientações do que fazer caso ela morresse..." (Enfermeira 5)

"Toda vez que eu vou para o plantão, especialmente agora no Covid, eu sei que a morte está presente" (Enfermeiro 16)

"É uma doença que abala muito o psicológico... porque a gente vê a quantidade de casos de pacientes morrendo... Então, tu internou por isso, é uma pressão psicológica, porque tu não sabe se vai sair dali vivo ou não. Então, a instituição contratou uma psicóloga para lidar com os pacientes e com os familiares. (...) Com nós é bem complicado. A não ser que tu vai e tu pede para conversar com a psicólogo, mas também a gente não tem muita abertura sobre isso, de dizer 'olha, estou me sentindo pressionada', é quase como se tu dissesse que não consegue fazer teu trabalho." (Enfermeira 1)

Como podemos perceber, durante a realização desta pesquisa, a pandemia de Covid certamente colocou os enfermeiros de frente com a possibilidade de enfrentar a própria morte. Não só em razão do alto número de óbitos vivenciados diariamente, mas porque pareceu impossível utilizar a estratégia de deixar no trabalho as emoções vivenciadas pelas mortes ante as proporções da pandemia. Os profissionais além de enfrentarem o aumento das mortes, também passaram a lidar com rígidos protocolos de segurança para evitar a contaminação. 
Veja a fala a seguir:

"É inevitável não falar da pandemia, porque tá muito forte... uma coisa que me chamava muito a atenção era a questão dos óbitos. A gente ter que tirar os óbitos da UTI num saco preto... antes eram todos os pacientes, depois foi sendo flexibilizado, até 21 dias, tinha que ser removido num saco preto. E tínhamos que fazer o reconhecimento no elevador. Era horrível! A gente mostrava o corpo para a família, era a pior parte de todas, porque a gente coloca o paciente no saco, deixava só a cabeça de fora, naquele saco preto... daí a gente botava um lençol branco por cima para ficar menos pior e a família, um familiar era paramentado, vinha no elevador e não podia encostar... gente...era horrível! Isso eu nunca vou esquecer! Nunca!" (Enfermeira 2)

"Colocar no dito saco preto - isso se tornou uma tortura para nós também. (...) Mas era protocolo. Para nós é difícil! Para nós é muito difícil... saber... Poxa vida, pode ser eu amanhã. Eu tenho que tirar tudo, vai sem roupa... sem nada, tu tem que colocar dentro de um saco... não é... (silêncio)" (Enfermeira 13)

Se antes da pandemia o cotidiano dos profissionais enfermeiros nas unidades de emergência e urgência já era árduo no que diz respeito ao número de mortes, sendo necessária maior atenção à saúde mental desses profissionais, a pandemia certamente demonstrou que os mecanismos de defesa criados podem não se sustentar no tempo.

\section{CONSIDERAÇÕES FINAIS}

A morte evidentemente está presente nos setores de emergência e urgência e, portanto, no cotidiano destes profissionais. É um fenômeno que abala a todos e há muita dificuldade para falar do assunto, um verdadeiro tabu. O objetivo deste trabalho era investigar a reação dos profissionais enfermeiros diante do processo de morrer e da morte, restando evidenciado que o manejo profissional com relação ao enfrentamento da questão da morte ainda está atrelada a uma questão extremamente subjetiva que atravessa a constituição sócio histórica do profissional enquanto produto da sociedade e do meio onde vive. Segundo Nely A. G. Nucci (2018, p. 69), "o modo como nos protegemos da perda pode ser o modo como nos distanciamos da vida".

A grande maioria dos profissionais têm dificuldades em identificar as reações que o processo de morrer e a morte lhes despertam porque não querem entrar em contato com essas emoções. Os profissionais entrevistados utilizam como defesa psíquica a negação e a racionalização, utilizam pronomes impessoais e linguagem técnica, tudo para criar uma barreira emocional e tornar a morte concreta, mensurável e distante, algo controlável, passível de não ser sentida, uma emoção não natural como dito por Kübler-Ross (2003). Foram reiteradas as falas no sentido de que a graduação não prepara para a quantidade de mortes que vão vivenciar e isso é um aprendizado solitário, no qual acreditam que pedir ajuda é se mostrar inapto a exercer a profissão. Dessa forma, o aparelho 
mental vai criando estratégias para suportar a sobrecarga emocional, o que a longo prazo pode trazer sérios prejuízos à saúde mental.

Foram limitadores desse estudo a realização durante um momento crítico da pandemia em que o tempo disponível dos profissionais era restrito, mesmo que o tempo médio de participação tenha sido de 15 minutos, e ter sido realizado no formato remoto sem que fosse possível a observação dos profissionais em seu local de trabalho.

Assim, sugere-se melhorias nos cursos de graduação, em especial inserindo-se a disciplina de tanatologia e proporcionando aos acadêmicos de enfermagem discussões e reflexões sobre o processo de morrer e a morte, bem como salientar durante a graduação a importância do cuidado com a própria saúde mental, onde fossem abordadas patologias como Burnout, transtornos ansiosos e depressivos. É necessário que os profissionais sejam também emocionalmente preparados para enfrentar as mortes e todos os aspectos relacionados a ela.

Sugere-se, ainda, a criação e/ou manutenção de serviços de psicologia voltados também para as necessidades dos profissionais (e não apenas para os pacientes), servindo de suporte para a comunicação das mortes às famílias, o que sem dúvida aliviaria a carga emocional depositadas nas equipes de emergência e urgência, mas também para acompanhar de forma terapêutica a própria equipe, em especial aqueles que ficam expostos por longo tempo de trabalho em unidades de emergência e urgência, como já foi dito.

Foi necessário a pandemia, um excesso, para demonstrar a necessidade e a importância do serviço de apoio psicológico voltado também aos profissionais e a necessidade de cuidado da saúde mental dos profissionais que trabalham nos serviços de urgência e emergência dos hospitais. É necessário a criação de espaços para que os profissionais possam compartilhar e elaborar suas angústias e sentimentos em relação à morte e ao processo de morrer, seja de forma individualizada ou em grupo. É através desses espaços que os profissionais podem desenvolver estratégias saudáveis de enfrentamento das situações de crise.

\section{REFERÊNCIAS}

Alencar, S., Lacerda, M., Centa, M. (2005). Finitude Humana E Enfermagem: Reflexões Sobre O (Des)Cuidado Integral E Humanizado Ao Paciente E Seus Familiares Durante O Processo De Morrer. Família, Saúde e Desenvolvimento, 7(2). doi: http://dx.doi.org/10.5380/fsd.v7i2.8045

Ariès, P. (2012). História da morte no Ocidente: da ldade Média aos nossos dias. (P. V. de Siqueira, Trad.). Rio de Janeiro: Edição Especial de Bolso Saraiva. (Trabalho original publicado em 1977)

Botega, N. J. (2015). Crise Suicida. Avaliação e Manejo. Porto Alegre: Artmed.

Caregnato, R. C. A., Mutti, R. (2006). Pesquisa qualitativa: análise de discurso versus análise de conteúdo. Texto e contexto - enfermagem [on line]. (15)4, 679-684. doi: http://dx.doi.org/10.1590/S0104-07072006000400017 
Cassorla, R. M. S. (2015). Abordagem em Psicodinâmica do Paciente Ansioso: Transtorno de Pânico Transtorno de Ansiedade Generalizada. In: Eizirick, C. L., Aguiar, R. W. de e Schestatsky, S. S. (org.) Psicoterapia de Orientação Analítica: Fundamentos Teóricos e Clínicos. (pp. 493-5112). Porto Alegre: Artmed.

D’Assumpção, E. A. (2011). Sobre o viver e o morrer. Manual de Tanatologia e Biotanatologia para os que partem e os que ficam. Petrópolis: Editora Vozes.

Goleman, D. Inteligência emocional. A teoria revolucionária que define o que é ser inteligente. (M. Santarrita, Trad). $74^{\underline{a}}$ edição. Rio de Janeiro: Editora Objetiva.

Gil, A. C. (2017). Como elaborar projetos de pesquisa. 6ª̂ed. São Paulo: Editora Atlas.

Kovacs, M. J. (2002). Morte e desenvolvimento humano. 4ª ed. São Paulo: Casa do Psicólogo.

Kübler-Ross, E. (2003). O túnel e a luz: reflexões essenciais sobre a vida e a morte. (M. F. Lopes, Trad.). Campinas, SP: $4^{\underline{a}}$ ed. Versus Editora. (Título original publicado em 1999).

Magalhães, M. V., Melo, S. C. de A. (2015). Morte Ee Luto: o sofrimento do profissional da saúde. Psicologia E Saúde Em Debate, 1(1), 65-77. Recuperado de http://psicodebate.dpgpsifpm.com.br/index.php/periodico/article/view/7

Mattos, T. de A. D., Lange, C., Cecagno, D., Amestoy, S. C., Thofehrn, M. B. e Millbrath, V. M. (2009). Profissionais de Enfermagem e o Processo de Morrer e Morte em uma Unidade de Terapia Intensiva. REME - Revista Mineira de Enfermagem, 13(3), 337-342, jul/set. Recuperado de http://reme.org.br/artigo/detalhes/197

Nucci, N. A. G. (2018) Educar para a morte: cuidar da vida. In: Fukumitsu, K. O. Vida, morte e luto. (pp. 62-74). São Paulo: Summus.

Oliveira, C. de, Nunes, M. F. O., Legal, E. J., Noronha, A. P. P. (2016). Bem-Estar Subjetivo: estudo de correlação com as Forças de Caráter. Avaliação Psicológica, 15(2), 177-185. Recuperado em 08 de novembro de 2021, de http://pepsic.bvsalud.org/scielo.php?script=sci arttext\&pid=S1677$04712016000200007 \& \operatorname{lng}=\mathrm{pt} \& \operatorname{lng}=\mathrm{pt}$.

Oliveira, J. C., Felipe, B. C. M., Barbosa, G. de O., Santos, T. P, Viana, J. S. (2020). Reflexões sobre o suporte emocional do enfermeiro no processo de tanatologia. Brazilian Journal of Health Review. Curitiba, 3(3), p. 4566-4576, may/jun. Doi: https://doi.org/10.34119/bjhrv3n3-053

Resolução do Conselho Federal de Medicina no 2173, de 23 de novembro de 2017 (2017). Define os critérios do diagnóstico da morte encefálica. Brasília, DF. Recuperado em 13 de setembro de 2020 de https://saude.rs.gov.br/upload/arquivos/carga20171205/19140504-resolucao-doconselho-federal-de-medicina-2173-2017.pdf

Resolução do Conselho Nacional de Educação/Câmara Ensino Superior no 03, de 07 de novembro de 2001 (2001). Institui Diretrizes Curriculares Nacionais do Curso de Graduação em Enfermagem. Brasília, DF. Recuperado em 29 de agosto de 2020 de http://portal.mec.gov.br/cne/arquivos/pdf/CES03.pdf

Resolução no 466, 12 de dezembro de 2012 (2012). Institui diretrizes e normas regulamentadoras de pesquisas envolvendo seres humanos. Brasília, DF. Recuperado em 21 de setembro de 2020 de https://conselho.saude.gov.br/resolucoes/2012/Reso466.pdf 
Resolução no 510, 7 de abril de 2016 (2016). Institui diretrizes e normas regulamentadoras de pesquisas envolvendo seres humanos. Brasília, DF. Recuperado em 21 de setembro de 2020 de https://bvsms.saude.gov.br/bvs/saudelegis/cns/2016/res0510 0704 2016.html

Ribeiro, M. C., Baraldi, S., Silva, M. J. P. da. (1998) A percepção da equipe de enfermagem em situação de morte: ritual do preparo do corpo "pós-morte". Revista da Escola de Enfermagem da USP [online]. 32(2), pp. 117-123. Doi: https://doi.org/10.1590/S0080-62341998000200004

Sadock, B. J., Sadock, V. A. (2007). Compêndio de Psiquiatria: Ciências do comportamento e psiquiatria clínica. Porto Alegre: Artmed.

Sancho Pereira Neto, H., Nunes Caixeta, B., Soares Melo, H. C., Antoniassi Junior, G. (2019). Promovendo Instituições Eficazes, Cenas Da Unidade De Terapia Intensiva: a morte e o morrer, sob o olhar do profissional de enfermagem. Psicologia E Saúde Em Debate, 5(1), 1-9. https://doi.org/10.22289/2446-922X.V5N1A1

Santos, F. S. (org.). (2007) A arte de morrer - Visões Plurais. Bragança Paulista: Comenius Editora.

Shimizu, H. E. (2007). Como os trabalhadores de enfermagem enfrentam o processo de morrer. Revista Brasileira de Enfermagem [online]. 60 (3), pp. 257-262, Doi: https://doi.org/10.1590/S0034-71672007000300002.

Silva, A. L. L. da, Ruiz, E. M. (2003). Cuidar, morte e morrer: significações para profissionais de Enfermagem. Estudos de Psicologia (Campinas) [online]. 20(1), pp. 15-25. Doi: https://doi.org/10.1590/S0103-166X2003000100002

Vandenbos, G. R. (organizador). (2015). Dicionário de Psicologia da APA. Porto Alegre: Artmed.

Yin, R. K. (2014). Estudo de Caso. Planejamento e Métodos. (D. Grassi, Trad.). 5ª ed. Porto Alegre: Bookman. (Título original publicado em 1984). 